\title{
\#informetwitter: análisis cualitativo del usuario avanzado de la red social
}

\author{
Mercedes AgüERo PÉREZ \\ Universidad Europea de Madrid \\ mariamercedes.aguero@uem.es \\ David LaVILla MuÑOZ \\ Universidad Europea de Madrid \\ davidjose.lavilla@uem.es
}

\begin{abstract}
Resumen:
Dentro del contexto de la denominada Sociedad del Conocimiento, resulta vital conocer en profundidad cómo interactúan los usuarios en las redes sociales y muy en concreto con la interfaz de Twitter. Hasta la fecha, se han realizado infinidad de investigaciones sobre la relevancia comercial, reputacional, de alcance o de penetración de este microblog. Casi todas ellas, han puesto de manifiesto la importancia de tener presencia personal o empresarial en esta red social. No obstante, con este informe realizado por Redbility, Influenzia, y la Universidad Europea de Madrid, se pretende reconocer cómo los usuarios emplean esta herramienta desde sus diferentes dispositivos y descubrir cuál es la manera más eficiente de participar en esta red social.
\end{abstract}

Palabras clave: Social Media; \#informetwitter; Twitter; redes sociales.

\section{\#informetwitter: qualitative analysis of the social network's advanced user.}

\begin{abstract}
:
Within the "Knowledge based society" context, it is essential to know how users interact in social networks and specially with the Twitter interface. Up to now, it has been the object of several scientific research and studies on the microblog's commercial relevance, reputation, significance or introduction. Almost all of them have shown the importance of personal or business presence in this social network. However, the report produced by Redbility, Influenzia and the Universidad Europea de Madrid, tries to show how users use this tool via differents devices and find out what is the most efficient way to participate in this social network.
\end{abstract}

Key Words: Social Media; \#informetwitter, Twitter, social network.

\section{Referencia normalizada:}

Agüero Pérez, M. y Lavilla Muñoz, D. (2014): \#informetwitter: análisis cualitativo del usuario avanzado de la red social. Historia y Comunicación Social. Vol. 19. Núm. Especial Marzo. Págs. 37-47.

Sumario: 1. Introducción. 2. Metodología. 3. Observación directa. 4. Análisis emocional. 5. Eyetracking. 6. Análisis morfosintáctico. 7. Conclusiones. 8. Referencias Bibliográficas. 9. Notas. 


\section{Introducción}

Comunicar bien y de forma efectiva en el siglo XXI es una tarea de obligado cumplimiento para el individuo o la empresa. En la era de la comunicación digital y de la web participativa, las organizaciones deben adaptarse a los nuevos soportes para poder sacar más provecho a su marca; y justamente con el uso de social media se puede conseguir este logro. Gracias a las redes sociales, muchos objetivos básicos de las compañías como la visibilidad, la reputación o la imagen personal o empresarial se pueden alcanzar de manera efectiva, aunque no se puede olvidar que su mal uso puede llegar a causar graves daños en la reputación personal o empresarial.

Por este motivo, el uso correcto de las TIC debe ser una prioridad en los objetivos que se marque tanto la empresa como el individuo a la hora de dar difusión a los mensajes que se pretendan comunicar. Además, se debe ofrecer una estrategia conjunta en la difusión del mensaje porque los usuarios de las redes sociales demandan coherencia, conexión y cohesión a la hora de difundir información.

Una de las redes sociales de más uso es Twitter, una plataforma de fácil manejo, versátil y eficaz que permite conversar horizontal y democráticamente a sus usuarios.

A día de hoy, se puede decir que Twitter es en algo más que una plataforma de generar contenidos y comunicarse con el cliente-usuario. Con ella, la empresa puede obtener más conocimiento de su cliente gracias a su flujo continuo y retroalimentación bidireccional. Su propio fundador, Jack Dorsey, en una entrevista concedida al diario El País en marzo de 2009, llegó a afirmar que Twitter va más allá del concepto de red social al uso.

No considero que Twitter sea una red social, sino una herramienta de comunicación. Puedes construir una red social encima de Twitter, ya que no son más que un directorio de nombres. A Twitter lo consideramos una plataforma de comunicación (Muñoz y Rivero, 2009).

Por todo lo anteriormente expuesto, y partiendo de la premisa de que este microblog es una plataforma de comunicación y que uno de los valores fundamentales es crear conversación o relación, se puede llegar a afirmar que Twitter es una herramienta fundamental en la estrategia de comunicación de la empresa en el plan de social media que se plantee, tal y como antes se ha mostrado. Fundamentalmente este es el caso porque Twitter es ya una fuente de contacto efectivo entre la empresa y su público objetivo.

Pero además, existen otros beneficios, si se toma en cuenta al experto en Social Media, Oscar Rodríguez Fernández.

Según este experto, con Twitter la empresa puede tener grandes ventajas a la hora de abordar eficiencia en la comunicación empresarial y personal. Porque con Twitter, como dice este experto, se puede obtener más visibilidad y atraer tráfico a la web corporativa. 
Con Twitter se genera conexión de nuevas audiencias y segmenta mejor al público objetivo para ofrecer a cada grupo la información que le interese. Se interactúa y conversa para reconocer la opinión que tienen sobre la empresa. Se ofrece contenido o servicios que no son posibles mostrar de otro modo y anuncia, por ejemplo, futuros eventos y establece un seguimiento de todo lo generado. Se obtiene más relevancia, al tratar de ser referencia. Se considera las necesidades y demandas de los usuarios y clientes (además, con un seguimiento adecuado se puede detectar, de manera proactiva, las futuras tendencias del mercado). Se conoce mucho mejor a su cliente o al que puede llegar a serlo (a su vez, se conocerá también mucho mejor a la competencia y lo que está haciendo en redes sociales). Se humaniza más la labor, ya que los usuarios detectan que la empresa está formada por personas e interactúan con ellos, les ponen cara y voz. (Rodríguez, 2011:21).

Además Twitter, como apunta en toda su obra este mismo autor, Óscar Rodríguez Fernández, es una herramienta de marketing de rentabilidad superior a cualquier otra tradicional porque con ella; se aumenta la transparencia; se refuerza y realza el compromiso de colaboradores y empleados; se intercambia información con el equipo de la empresa; se refuerza la implicación de las personas; se consigue un aumento de ventas a medio y largo plazo. Y por último, pero no menos importante, siguiendo las conversaciones, la empresa puede detectar a los líderes de opinión, la actividad y opinión de empresas y usuarios de interés para su propia actividad.

\section{Metodología}

Pero pueden surgir numerosas dudas a la hora de sacar partido a esta herramienta de comunicación o a la hora de constatar que Twitter es una herramienta eficaz en la transmisión de mensajes y de poner en contacto a los dos participantes, empresa y usuario, y que ambos dialoguen de manera eficaz y segura.

Por este motivo la empresa Redbility, junto con Influezia y la Universidad Europea de Madrid desde su Máster Universitario de Periodismo Digital y Redes Sociales, realizaron una investigación para conocer mejor al usuario de Twitter y determinar su comportamiento y comprobar la efectividad en términos cualitativos de Twitter.

Redbility se encargó de las herramientas tecnológicas necesarias para realizar el estudio, con el fin de proponer su posterior análisis de la misma extracción de los datos. Influezia, aportó el conocimiento de los usuarios expertos en el uso y manejo de la red social y el Máster de Periodismo Digital y redes Sociales de la Universidad Europea de Madrid el sello de calidad universitaria, su certificación y el compromiso de generar análisis académico a partir de los datos obtenidos.

De tal modo que Redbility empleó diferentes técnicas cualitativas para analizar la muestra -que constaba de 35 participantes divididos en usuarios expertos (heavy users) y usuarios medios (médium users),- y analizar así su información. Entre las técnicas se encontraban la observación directa, el análisis emocional, el análisis 
morfosintáctico y el eyetracking. Y se dividió al sujeto de estudio, según su dispositivo de uso.

Todos estos usuarios fueron extraídos de la base de datos que maneja Influenzia, empresa líder en España, en cuanto usuarios expertos, con repercusión mediática dentro de Internet, de un universo de 130 usuarios con las características solicitadas para la realización de un estudio de este fin.

Con Twitter se genera conexión de nuevas audiencias y segmenta mejor al público objetivo para ofrecer a cada grupo la información que le interese. Se interactúa y conversa para reconocer la opinión que tienen sobre la empresa. Se ofrece contenido o servicios que no son posibles mostrar de otro modo y anuncia, por ejemplo, futuros eventos y establece un seguimiento de todo lo generado. Se obtiene más relevancia, al tratar de ser referencia. "Se considera las necesidades y demandas de los usuarios y clientes (además, con un seguimiento adecuado se puede detectar, de manera proactiva, las futuras tendencias del mercado). Se conoce mucho mejor a su cliente o al que puede llegar a serlo (a su vez, se conocerá también mucho mejor a la competencia y lo que está haciendo en redes sociales). Se humaniza más la labor, ya que los usuarios detectan que la empresa está formada por personas e interactúan con ellos, les ponen cara y voz. (Rodríguez, 2011:21).

Para realizar todo este proceso y para elegir los soportes se tuvo como referencia a ComScore ya que en su último informe ratificaba que el acceso a redes sociales desde el móvil crece un 45\% solo en el año 2012 y el $62 \%$ de los usuarios de redes sociales desde el móvil acceden casi a diario (ComScore, 2013). Además, siguiendo este mismo estudio, los usuarios únicos de Twitter desde el PC aumentaron en 2012 en un $23 \%$ frente a un $51 \%$ de aumento en los usuarios de Twitter de smartphone.

Asímismo, se optó por incluir la tableta como tercer dispositivo ya que casi 4 millones de españoles que ya disponían de un smartphone en diciembre de 2012, también adquirieron una tableta.

En lo que respecta a la selección de la muestra, de ámbito nacional, se eligieron distintos perfiles según el área de conocimiento de la que eran líderes de opinión (relacionadas todas con comunicación, tal y como se ha expuesto con anterioridad) por: cantidad de seguidores, influencia de los mismos dependiendo de la cantidad de respuestas y viralidad resultante de los mensajes que ellos redactaban, aunque algunos de los usuarios tenían pocos seguidores por restricción personal o porque no interactuaban demasiado con la herramienta Twitter pero sí que la información que generaban producía repercusión entre los usuarios de la red. De tal forma que la muestra quedaba conformada por líderes de opinión seleccionados de una base de datos anteriormente expuesta con las mismas características, solicitando la presencialidad para la realización del test de los 35 usuarios mencionados.

Además, se dividió a los 35 usuarios por tipos, siendo cada categoría el 50\% y por herramientas y dispositivos utilizados. Se optó por estos perfiles con el fin de ofrecer en el estudio una información más completa y más profesional ya que las recomendaciones que se extrapolarán de la investigación estarán destinadas al ámbito profesional. 
Para la clasificación de usuarios avanzados (heavy users) y usuarios medios (medium users) se sigue la que propone el informe de AIMC: navegantes en la red (del que se hablará más tarde) que propone: que los heavy user de la población internauta son, en un mayor número, hombres, más jóvenes, con mayor nivel de estudios, más urbanos, más activos, más tiempo conectados (desde casa y en especial desde otros sitios) y con mayor experiencia en Internet.

Las cuatro técnicas cualitativas que se utilizaron para la realización del estudio, se eligieron por su complementariedad entre ellas y por la posibilidad de ofrecer la visión completa del comportamiento de los usuarios utilizando Twitter, además de favorecer al investigador el reconocimiento de unos parámetros comunes que permitan aportar recomendaciones a las empresas.

\section{Observación directa}

En primer lugar se emplea esta técnica porque la mejor manera de acercarse a un problema es mediante la observación del mismo. Según Báez y Pérez de Tudela esta técnica permite observar la realidad in situ y sacar conclusiones de la manera más aséptica posible siempre desde el punto de vista del investigador.

Persigue la descripción, más que la explicación. Es una técnica empírica, intensiva y directa de aprehensión de las realidades, dado que el investigador conoce no por lo que otros le cuentan (grupos, entrevistas...) sino por lo que percibe directamente, sin intermediación, tal como el fenómeno se da en la realidad. Luego informará sobre lo observado de la forma más aséptica posible, siendo tan prolijo como sea necesario en la especificación detallada de lo visto y oído. Para conocer el fenómeno el investigador se desplaza al lugar en el que éste se da, con la pretensión de enterarse in situ y de primera mano, a diferencia de lo que sucede en la experimentación, en la que las condiciones naturales pueden alterarse o, incluso, crearse artificialmente. (Báez y Pérez de Tudela, 2009:173)

La observación como técnica de investigación tiene su origen académico en la antropología, tanto en la etnografía como en la etnología y su objetivo es ofrecer una visión lo más cercana posible a la realidad del comportamiento del sujeto o de los grupos de sujetos. La observación, por su forma de abordarse, se puede realizar de las siguientes formas: en cuanto a la observación participativa, el investigador se mezcla con los sujetos a estudiar en el contexto que se necesite para poder esclarecer las hipótesis fijadas; en lo que respecta a la observación no participativa, la recogida de los datos la hace el investigador directamente, también observará a los sujetos o al grupo de forma directa pero no se mezclará con él o ellos y por lo tanto no se necesita que el grupo lo reconozca. En este caso se optó por la observación no participativa, de tal modo que el observador tan solo proponía al sujeto de estudio que realizase una consulta común delante de la interfaz de uso habitual de el microblog Twitter.

Por supuesto que la observación directa tiene una serie de ventajas y por eso se ha utilizado en el ya mencionado \#informetwitter. Mediante la observación directa, 
los datos los recoge directamente el investigador, se ofrece el comportamiento de las personas tal y como se realiza en su día a día, el fenómeno necesita de esta técnica para que se pueda estudiar y con otra sería más complicado reproducirse. No obstante, no hay que dejar de lado que siempre existe una cierta subjetividad en el investigador a la hora de la recogida de los datos, pero para que esto no se produjera, o que se redujera lo máximo posible, se decidió que fuera otro investigador que no estuviera presente en la toma de datos el que estudiara al sujeto una vez volcados y extraídos los mismos.

\section{Análisis emocional}

En segundo lugar se empleó el análisis emocional. Esta técnica es muy útil para el estudio de las reacciones ante determinadas circunstancias, como es el caso de las reacciones del individuo frente a Twitter. $Y$ es que es indispensable utilizar varias herramientas de investigación que ayuden a abarcar el fenómeno de manera completa.

Desde sus inicios, el neuromarketing, la aplicación a las investigaciones de mercado de la neurociencia, ha intentado reconocer el proceso que hay desde un determinado estímulo hasta la reacción específica del usuario o consumidor. Con esta técnica se intenta relacionar las emociones de los individuos con los aspectos sensoriales, fisiológicos y congnitivos y se realiza midiendo una serie de variables, tal y como lo explican M. Jesús Merino y Estefanía Yagüez:

La excitación, es decir, el nivel de activación de la persona. Se produce como respuesta a los estímulos externos en los neurotransmisores por las hormonas. El valor, ofreciendo una discriminación sobre las emociones positivas o negativas. La carga congnitiva, referido al esfuerzo que tiene que realizar el cebrebro para aprender algo o realizar una tarea. (Merino y Yágüez, 2012:74-75).

Además, para esto se aplican las siguientes tecnologías basadas en el análisis neurológico recomendadas por Merino y Yagüez: por un lado las tecnologías biométricas que facilitan la medición del ritmo cardiaco, pueden captar los cambios de ritmos derivados de la reacción a determinados estímulos y fisiológicas, que miden la respuesta emocional de la piel gracias a la resistencia eléctrica y al grado de conductividad que tiene.

\section{Eyetrancking}

Así pues de la segunda se deriva la tercera, el eyetracking, ya que es una de las técnicas de investigación más eficaz para evaluar la usabilidad de un sitio web.

En este caso, el eyetracking pretendía calcular dónde está mirando el usuario. La gran aportación de esta técnica es que posibilita, a través de rayos infrarrojos, la 
identificación de las partes en las que el individuo muestra más atención y fija la vista durante más tiempo. Gracias a un código de colores que arroja el eyetracking, se identifica qué partes de la web han recibido más atención (los colores cálidos) o menos (colores fríos) o en los que el sujeto se ha detenido más o menos tiempo. También, facilitan las rutas que siguen los ojos desde que entran en contacto con el documento hasta que finaliza. Todo esto resulta de vital importancia en un interfaz como el de Twitter, tan sencillo, como usable y directo.

El eyetracking sirvió en este caso entonces, fundamentalmente, para obtener datos sobre la atención visual porque también el comportamiento depende de aquello a lo que los individuos prestan atención.

Esta técnica se utiliza para saber lo que la gente mira no tendría valor si no nos dice algo acerca de su comportamiento. Afortunadamente, gracias a la teoría mindeye, que sostiene que lo que la gente mira y lo que está pensando tiende a ser lo mismo. Y continúan diciendo que la gente mira a los elementos de diseño en los que están interesados, y cuanto más miran estos elementos más están interesados en ellos. (Nielsen y Pernice, 2009: 18).

En este caso, analizando el comportamiento del usuario ante Twitter, interesa saber qué informaciones, imágenes o partes de la pantalla interesan o gustan más para posteriormente, poder realizar aportaciones a las empresas que les reporten algún tipo de beneficio reputacional o comercial.

\section{Análisis morfosintáctico del mensaje}

Por último, como última técnica cualitativa, se utilizó el análisis morfosintáctico del mensaje porque, como ya se ha indicado, un mensaje de Twitter son 140 caracteres, caracteres que forman parte de una conversación y que su composición puede determinar que el receptor tenga un juicio positivo o negativo de la persona o empresa que lo emite. Para determinar si existe una composición que pueda ejercer una reacción positiva en el receptor se ha realizado este tipo de análisis. Con esta técnica se busca analizar el tipo de palabras que se utilizan en un sintagma determinado, la función que realizan y la relación que ejercen entre ellas. De la correcta ordenación y jerarquía de las palabras puede depender la interpretación y la comprensión de los textos. Existen varios modelos para realizar una análisis morfosintáctico: mediante un esquema, un esquema redactado o una redacción explicando cada una de las palabras y la función que tienen en el sintagma analizado. En este caso se utilizó un esquema con los tweets que se generaban desde el lugar de la observación. Algo que hay que tener muy en cuenta en la redacción de un mensaje que se va a emitir en Twitter es la economía en las palabras, esta premisa no se debe olvidar debido a la propia idiosincrasia de la herramienta. El tipo de palabras que se usan, el orden y la gradación son una de las preocupaciones y ocupaciones más importante que debe tener la empresa al utilizar Twitter. Para generar una óptima comunicación, como 
regla general, las frases deben ser breves y claras pero sin descuidar el estilo con el que están redactadas. Se debe mantener en la escritura de mensajes las directrices de la denominada netiqueta ${ }^{1}$, estas directrices parten de un consenso a nivel mundial que rige el comportamiento en Internet. En estas normas de comportamiento (en la red es fundamentalmente lingüístico y en Twitter casi de manera exclusiva) se tendría que tener en cuenta, siguiendo indicaciones de la profesora $\mathrm{M}^{\mathrm{a}}$ Elena Gómez y del profesor Luis Guerra², lo siguiente:

Ser conscientes de la audiencia. Tengamos presente en cada momento a quién hablamos o escribimos. En la red nuestro público puede ser individual o colectivo (...). Analizar si en nuestras comunicaciones debemos emplear el tú, el usted o el vos. La red no implica necesariamente que haya que comportarse de manera distinta a como lo haríamos en otros contextos escritos u orales. Cuidar la forma de expresarnos. Dado que el contexto no es necesariamente compartido, el mensaje ha de ser lo más unívoco posible. Intentemos que nuestros lectores entiendan exactamente lo que hemos querido decir. Las normas (de ortografía, léxico, sintaxis) garantizan el empleo de unos estándares comunes. Ser cortés también significa facilitar la descodificación por parte de quien recibe el mensaje. Ser claros. Más específicamente, seamos concisos, hagamos contribuciones relevantes y ciertas, ofrezcamos un texto bien estructurado. Tener en cuenta las diferencias culturales. (...). El anonimato no es razón para la descortesía. (...). (Guerra y Gómez, 2012:52).

Por tanto, es importante la revisión tanto de las palabras utilizadas y sus funciones como si se han mantenido las normas de cortesía que deben de guiar los actos comunicativos de la empresa porque la forma de redacción de los mensajes también repercute en la reputación en línea.

\section{Conclusiones}

El enfoque de la investigación se sustentó en la identificación de los elementos, en las temáticas o prácticas que hacen de un tweet un elemento de comunicación para los usuarios de Twitter, y se llegaron a estas conclusiones:

PRIMERA: se identificaron tres perfiles principales del microblog Twitter: los profesionales de las redes sociales, referidos a todos aquellos profesionales que hacen de este sitio su canal principal de comunicación -como los gestores de comunidades virtuales o los bloggers, los profesionales en las redes sociales-aquellos que emplean las redes como canal de información de su trabajo diario y los particulares, aquellos que usan Twitter de manera particular y que en ocasiones lo utilizan también de manera profesional o que incluyen temas referentes a su profesión para interactuar.

1 Palabra compuesta por el término francés "étiquette" que significa etiqueta y por el término inglés "net" que significa red.

2 GOMEZ, Ma Elena y GUERRA, Luis. La etiqueta en la red: la cortesía en la comunicación digital en TASCÓN, Mario (dir.). Escribir en Internet. Guía para los nuevos medios y las redes sociales. Fundeu BBVA 2012. (p. 52). 
SEGUNDA: se observó que la eficacia del tweet depende de muchas variables como el tema tratado o el tono empleado. Del mismo modo, se identificó como tonos más exitoso el informativo, sin dejar a un lado la generación del mensaje desde la ironía.

TERCERA: se identificó como clave de éxito la hora del día en que se emite el mensaje, siendo la primera hora de la mañana o la última hora del día las franjas horarias en las que los mensajes tienen más posibilidades de éxito, ya que los usuarios interactúan en estos momentos con más tranquilidad y detalle.

CUARTA: se detectó que la corrección lingüística de un tweet genera muchas más posibilidades de ser consumido. Y es que la construcción del mensaje ha de seguir un orden gramatical lógico y correcto.

QUINTA: se llegó a la conclusión de que el consumo de los tweets es diferente desde cada dispositivo. Por ejemplo, desde un dispositivo en movilidad se presta más atención al cuerpo del tweet pero si se consumen desde un PC hay que tener en cuenta otros aspectos como el avatar, el nick o el nombre de la cuenta.

SEXTA: se concluyó en el estudio que la emoción en Twitter es importante, ya que el $97 \%$ de los tweets que convirtieron durante la prueba generaron una activación emocional en los lectores. Aunque no sólo la lectura de los tweets se detectó que activa emocionalmente a los usuarios, también lo hicieron los siguientes eventos: la escritura de un mensaje, la consulta de un tweet propio recién escrito, el visionado de una foto propia, una excesiva espera durante la carga de la página web a la que dirige un enlace externo o un formato publicitario intrusivo que bloquea temporalmente la interacción de los usuarios.

Asimismo, el informe tras la conclusión, como apartado significativo, expone recomendaciones tras su análisis cualitativo y entre ellas se destacan las siguientes:

PRIMERA: se debe cuidar especialmente el tiempo de descarga de los archivos enlazados desde el cuerpo de los mensajes.

SEGUNDA: el propio enlace debe transmitir adecuadamente el tipo de contenido del que se trata.

TERCERA: la biografía o datos personales del usuario es un elemento importante a la hora de que un usuario profesional tome la decisión de seguirle

CUARTA: se debe cuidar la redacción del tweet, haciendo un uso gramatical correcto aunque es importante dar un aspecto informal al mismo.

QUINTA: los hashtags no aseguran que te vayan a leer (el $56 \%$ de los tweets que han convertido los tenían, pero el $44 \%$ no) pero parece que pueden ayudar a contextualizar los mensajes porque el buscador se emplea para indagar temáticas y porque pone en relación un tweet con un tema que alguien está buscando. 


\section{Bibliografía}

\subsection{Libros:}

BÁEZ y PÉREZ DE TUDELA, J. (2009). Investigación cualitativa. Madrid: ESIC Editorial. P. 173.

MERINO, M. J. y YAGÜEZ, E. (coord.) (2012). Nuevas tendencias en investigación y marketing. Madrid: ESIC Editorial. p. 74-75.

NIELSEN, J., PERNICE, K. (2010). Eyetracking Web Usability. Pearson Education. p. 9).

RODRÍGUEZ FERNÁNDEZ, Ó. (2011). Twitter. Aplicaciones profesionales y de empresa. Madrid: Ediciones Anaya Multimedia. p. 21.

8.2 Capítulo de libro:

GÓMEZ, M.E. y GUERRA, L. (2012). "La etiqueta en la red: la cortesía en la comunicación digital. En TASCÓN, Mario (dir.) (2012). Escribir en Internet. Guía para los nuevos medios y las redes sociales. Madrid: Fundeu BBVA p. 52.

8.3 Publicaciones web:

COMSCORE. Spain Digital. Future in Focus 2013. Abril 2013. Información disponible en: http://www.comscore.com/Insights/Presentations_and_Whitepapers/2013/2013_Spain_Digital_Future in_Focus (Consulta: 25-09-2013).

El País. (25/03/2009). [29-3-2009]. MUÑ̄̄, R., RIVEIRO, A.: Twitter no es una red social sino una herramienta de comunicación. http://tecnologia.elpais.com/ tecnologia/2009/03/25/actualidad/1237973279_850215.html

\section{Los Autores}

Mercedes Agüero (Madrid, 1971) es Directora Académica y profesora de la Facultad de Artes y Comunicación de la Universidad Europea de Madrid. Sus temas de investigación se centran en la comunicación corporativa, la reputación corporativa y gestión de la reputación en línea. Ha estado vinculada profesionalmente a distintas consultoras de comunicación, consultoras de estrategia y agencias de comunicación.

David Lavilla (Madrid, 1971) es profesor titular de Comunicación Digital y Nuevas Tendencias en la UEM y dirige del Máster Universitario de Periodismo Digital y Redes Sociales. Además es Responsable de Programas para las todas las titulaciones de Publicidad y Comunicación Audiovisual en la Universidad Europea de Madrid. Académicamente ha impartido docencia en diferentes escuelas de negocios y en varias universidades españolas y extranjeras. Sus líneas de investigación -algunas financiadas por el Estado español, algunas por la CAM y otras con financiación 
empresarial- giran en torno al humano y a su interactuación con la máquina. Actualmente codirige un proyecto sobre uso el uso emocional de Twitter para la UEM con Influezia y Redbility. 